Research article

\title{
An assessment of the effectiveness of a long-term ecosystem restoration project in a fynbos shrubland catchment in South Africa
}

\author{
Jennifer M. Fill ${ }^{\text {a, }}{ }^{*}$, Greg G. Forsyth ${ }^{\mathrm{b}}$, Suzaan Kritzinger-Klopper ${ }^{\mathrm{a}}$, David C. Le Maitre ${ }^{\mathrm{b}}$, \\ Brian W. van Wilgen ${ }^{a}$ \\ a Centre for Invasion Biology, Department of Botany and Zoology, Stellenbosch University, Private Bag X1, Matieland, 7602, South Africa \\ ${ }^{\mathrm{b}}$ Centre for Invasion Biology, Natural Resources and the Environment, Council for Scientific and Industrial Research, P.O. Box 320, Stellenbosch, 7600, South \\ Africa
}

\section{A R T I C L E I N F O}

\section{Article history:}

Received 25 May 2016

Received in revised form

8 September 2016

Accepted 24 October 2016

Available online 1 November 2016

\section{Keywords:}

Acacia

Best practice

Ecosystem management

Invasive alien species

Pinus

\begin{abstract}
A B S T R A C T
The long-term effectiveness of ecological restoration projects is seldom reported in the scientific literature. This paper reports on the outcomes of ecosystem restoration following the clearing of alien Pinus plantations and associated alien plant invasions over 13 years from an 8000 ha mountain catchment in the Western Cape Province, South Africa. We examined the goals, methods and costs of management, and the ecological outcomes in terms of reduced alien plant cover and native vegetation recovery. While the goals were not explicitly formulated at the outset, they were implicitly focussed on the conservation of water resources, the restoration of biodiversity, and the provision of employment. Initially, most ( $>90 \%$ of the area) was occupied by Pinus and Acacia invasions, mostly at low densities. The cost of control (initial clearing and up to 16 follow-up visits to remove emergent seedlings) amounted to almost ZAR 50 million (14 ZAR 1US\$). Although the cover of alien plants was greatly reduced, over 1000 ha still support dense or medium invasions ( $>25 \%$ cover), and the area occupied by scattered Pinus plants increased by over 3000 ha to $>5700$ ha. A reliance on passive restoration had not yet resulted in full recovery of the natural vegetation. The mean number of species, and total projected canopy cover on $50 \mathrm{~m}^{2}$ plots was lower in cleared than in comparable reference sites with pristine vegetation (21 vs 32 species/plot, and 94 vs $168 \%$ cover respectively). While the project is ongoing, we conclude that the entire area could revert to a more densely-invaded state in the event of a reduction of funding. Several changes to the management approach (including the integrated use of fire, a greater use of power tools, and active re-seeding of cleared areas with indigenous shrubs) would substantially increase the future effectiveness of the project and the sustainability of its outcomes.
\end{abstract}

๑) 2016 Elsevier Ltd. All rights reserved.

\section{Introduction}

Human-induced transformation of ecosystems accelerated during the latter half of the 20th century, leaving very few areas unaffected. The situation has reached a point where conscious trade-offs need to be made regarding the optimal configuration of landscapes that will deliver the most benefit to humanity, in the form of ecosystem services and the protection of biodiversity (Millenium Ecosystem Assessment, 2005). As a result, many projects worldwide seek to restore degraded or transformed ecosystems to a condition where they will deliver an arguably better set of

\footnotetext{
* Corresponding author.

E-mail address: jenna999@gmail.com (J.M. Fill).
}

benefits in future (Perring et al., 2015; Stanturf et al., 2014; Suding et al., 2015).

Successful restoration efforts depend on setting specific goals and implementing well-planned, effective operations. Restoration attempts should set clear objectives (Clewell and Aronson, 2007), and then assess whether or not progress towards achieving those goals is being made (Holl and Aide, 2011; Sainsbury et al., 2000). Most assessments of restoration efforts focus on ecological aspects of restoration activities (Brudvig, 2011), but how the projects are implemented and managed should also be evaluated (Suding et al., 2015). Regular monitoring will inform decisions on the allocation of limited resources, and on adaptive management (Epanchin-Niell and Hastings, 2010; Holl and Aide, 2011; Sainsbury et al., 2000), but this is seldom done (Ruiz-Jaen and Aide, 2005). The documentation of case studies and their outcomes over the long-term is 
therefore desirable for illustrating how effective they are (Menz et al., 2013; Suding et al., 2015; Wortley et al., 2013).

We took advantage of a rare opportunity to examine an ongoing long-term restoration effort in a South African mountain catchment. The land had been used for pine plantation forestry from the 1930s. Pine trees (genus Pinus) provide valuable timber, but are also invasive, spreading to adjacent unplanted areas (McConnachie et al., 2015) and impacting negatively on water resources (Le Maitre et al., 1996). In the late 1990s, a decision was taken to phase out plantation forestry. The plantations and surrounding land in the catchment were cleared of alien vegetation and restored as part of the South African government's national invasive species control program (Working for Water, van Wilgen and Wannenburgh, 2016). Since 1995, this programme has created jobs for impoverished workers by contracting out invaded areas for clearing projects (Koenig, 2009). The goals of the program are to restore the native fynbos (shrubland) vegetation, to enhance water runoff, protect biodiversity and provide employment (van Wilgen and Wannenburgh, 2016). Billions of rands have been spent on alien tree and shrub control across the country, improving water yield and providing employment (Marais and Wannenburg, 2008).

The value of the restoration scheme described here hinges on the removal of invasive alien plants (including plantation trees) and subsequent restoration of natural vegetation. In this study, we assessed the outcomes of ecosystem restoration following the clearing of Pinus plantations and alien plant invasions in the surrounding landscape over 13 years from the upper catchment of the Berg River in the Western Cape Province, South Africa. We examined the goals of restoration, the methods employed to achieve the goals, the costs of management, and the ecological outcomes in terms of reduced alien plant cover and native vegetation recovery. Based on this assessment we make recommendations for improving management in future.

\section{Methods}

\subsection{Study areas}

We assessed restoration activities in the upper Berg River catchment in the Western Cape Province, South Africa (33 $56^{\prime} \mathrm{S}$, $19^{\circ} 02^{\prime} \mathrm{E}$; Fig. 1). Mean annual rainfall is $\sim 1500 \mathrm{~mm}$, and the natural vegetation is sandstone fynbos shrublands, ranging in height from 0.5 to $2.5 \mathrm{~m}$ (Rebelo et al., 2006). The terrain is rugged and mountainous, with many steep slopes. Soils in the area are composed of coarse sands derived from sandstones of the Table Mountain Group (Cape Supergroup), and are mostly shallow and rocky. Detailed soil profiles are provided in van Wilgen and Kruger (1985). The project area covered about 8000 ha, about $25 \%$ of which had been in plantation (Fig. 2). Lower, relatively less steep portions of the catchment had been planted as early as the 1930s with pines, primarily Pinus pinaster and $P$. radiata. Invasive alien Acacia trees and shrubs, predominantly A. longifolia, also occurred in the unplanted parts of the study area, notably along drainage lines and floodplains of the Berg River.

From the late 1960s, the Department of Forestry conducted invasive plant clearing operations throughout the Berg and neighbouring catchments, but records of these control operations have not survived. In 2001, following a severe fire in 1999 that burned most of the catchment, the state leased the plantation to the private forestry company Mountain to Ocean (MTO). The privatisation of timber plantations was based on economic assessments of their viability, and roughly 40000 ha of plantations in the Western Cape were considered economically unviable and were earmarked for deforestation and transfer to conservation authorities (Louw, 2004, 2006). Because of anticipated financial loss from these plantations due to their unviability as well as the proposed construction of the Berg River dam, MTO harvested the standing timber from most of the planted area between 2001 and 2004. When MTO withdrew in 2005, Working for Water appointed the Cape Winelands District Municipality to implement alien plant control operations in the upper Berg River catchment (Fig. 2). These operations included follow-up on cleared plantations to remove regrowth, as well as clearing all invasive alien trees and shrubs from the adjacent catchment and floodplains that had not been afforested.

We assessed the effectiveness of clearing on vegetation recovery by comparing sites in the upper Berg River catchment to nearby areas where vegetation survey data were available. These included a site at Jonkershoek (McDonald, 1985), and one at Zachariashoek (van Wilgen and Kruger, 1985, Fig. 1). The geology and soils are similar to the Berg River catchment; mean annual rainfall is $1700 \mathrm{~mm}$ at Jonkershoek, and $1500 \mathrm{~mm}$ at Zachariashoek. The Zachariashoek site had historically been invaded by alien shrubs in the genus Hakea, which were cleared in the late 1960s (van Wilgen and Kruger, 1981), while the Jonkershoek site had no history of invasion.

\subsection{Goals of management}

The goals of management, and the methods used to achieve those goals, would ideally be set out in a management plan. However, there was no formal management plan for this project area. In 2002, a business plan had been written for a project in an adjacent area of the catchment. Although the Working for Water program goals were alluded to, the document included no specific, measurable objectives. We therefore attempted to document the management goals by reviewing a number of sources. The sources included assessments of the extent of the alien plant problem, and the magnitude of its impacts, published in the peer-reviewed literature; annual plans of operation that provided details of control operations; a spatial database of alien plant distribution and cover, and the costs of control; and interviews with project managers, including the project manager who had overseen the Berg River operations since their initiation in 2001.

\subsection{Elements of best practice, and control methods used}

We evaluated the methods used to control alien plants in the Berg River project by comparing them to approaches that would be considered to be best practice. These methods included mechanical and chemical control, biological control, the development of schedules for follow-up treatments, the integrated use of fire, and the spatial configuration of control interventions. The elements of best practice were obtained from studies and reviews published in the peer-reviewed literature, and the approaches actually employed were obtained from a review of the spatial database, as well as through interviews with project managers.

\subsection{Extent, cost and effectiveness of control}

We obtained information on the extent and cost of control from the Department of Environmental Affairs' spatial database. This database delineates fixed management units on which control operations (initial clearing and follow-up) are carried out. Each management unit has an estimate of alien plant cover for each species present; cover is assessed when the unit is first worked on, and re-assessed prior to any subsequent follow-up clearing. The records covered 13 years (2001-2014). Individual assignments on management units were contracted out to service providers, who were paid on completion of tasks assigned. The cost of each 


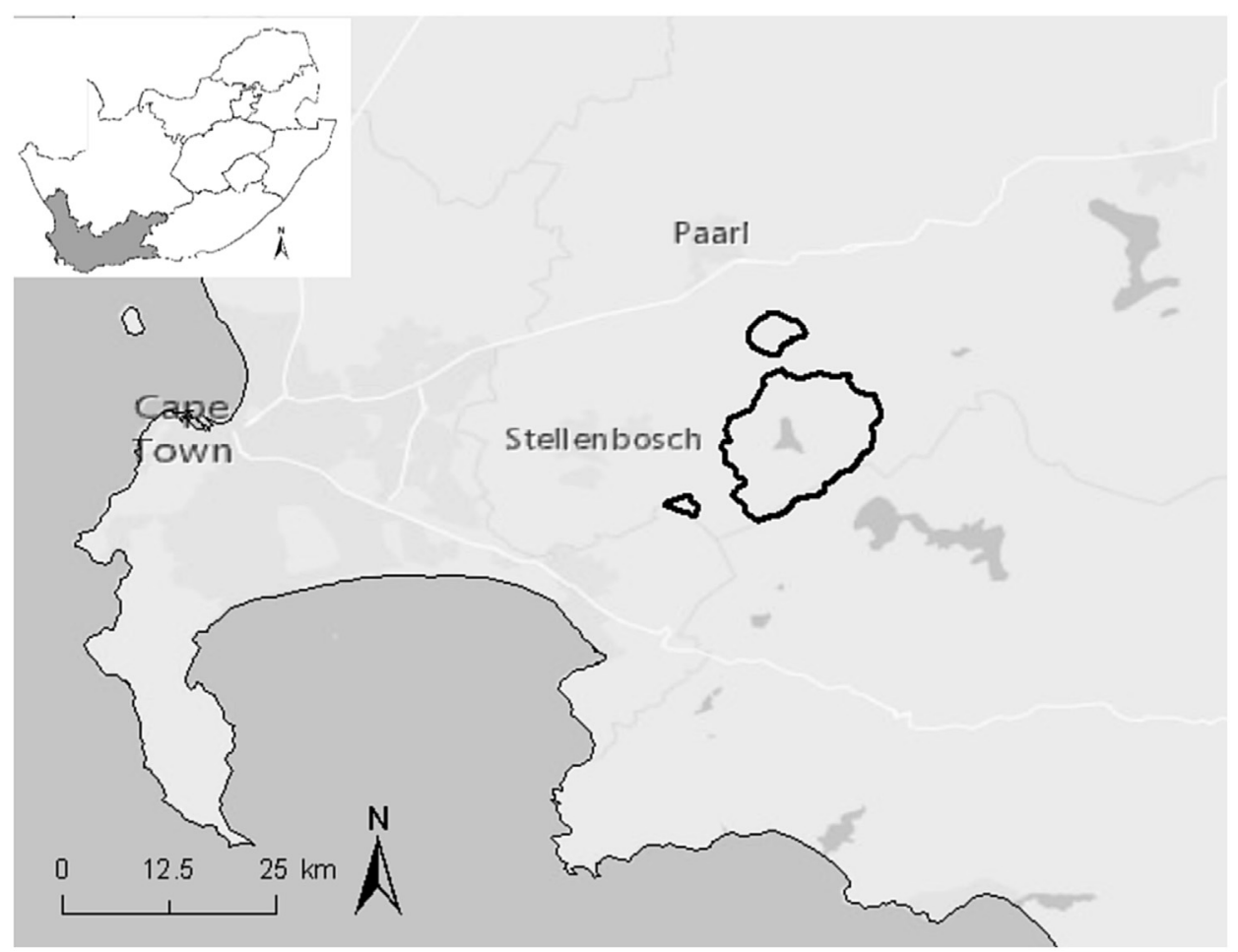

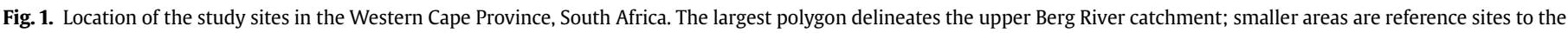
north (Zachariashoek) and southwest (Jonkershoek). Service Layer Credits: ESRI, HERE, DeLorme, MapmyIndia.

assignment was determined based on the species present, and their cover, and costs were recorded on the database. For a given unit, we assigned all of the cost of each treatment to the dominant species (the species with the greatest cover) addressed in that treatment. In our assessment, we differentiated between control efforts within the former plantation area and in surrounding natural vegetation. In 2012, a decision was taken to assign the clearing of relatively inaccessible areas (at higher altitudes and on steeper slopes) to specialized "high altitude teams". These teams were managed separately from other control efforts, and while costs were recorded, there was no record of the area that was treated, or the identity of species and their cover. We assigned $70 \%$ of the costs of high altitude teams to Pinus and $30 \%$ to Acacia on the recommendation of the project manager. We used the annual consumer price index to inflate monetary amounts to 2015 South African rands (ZAR; 1 US\$ 14 ZAR). The monetary amounts in the database included labour and herbicides, but did not include the costs of overheads. Conservation agencies typically add 35\% to the clearing costs to account for overheads (van Wilgen et al., 2016), and we added this amount to actual costs to cover overhead expenses such as on transport, equipment, supervision, and administration. To assess effectiveness, we examined the change in cover between successive treatments for the two primary invasive genera, Acacia and Pinus, from the initiation of clearing activities in 2001 until 2014.

\subsection{Recovery of natural vegetation}

The recovery of natural vegetation was assessed on plots in the study area, and was compared to similar data collected from nearby reference areas (Fig. 1). All study plots in the Berg River catchment last burned between 2005 and 2010, so that the post-fire age at the time of the survey was between five and ten years, and all of the component species would have been large enough to be identified (van Wilgen and Forsyth, 1992). At the time of surveys in the reference areas, the post-fire age ranged from six to 25 years at Zachariashoek, and was 29 years at Jonkershoek. We randomly located 15 plots $(5 \times 10-\mathrm{m})$ in formerly planted areas ("cleared plantation" plots) and 15 plots in unplanted areas ("cleared fynbos" plots). We listed all plant species present in each plot and assigned a cover class to each species on the Braun-Blanquet scale (Küchler, 1967). We randomly selected 15 plots from each of the reference sites, where the data had been collected in an identical manner. We refer to the previously invaded and cleared Zachariashoek plots as "reference disturbed" and to the undisturbed Swartsboskloof plots as "reference pristine".

We converted Braun-Blanquet cover classes to the midpoints of each class prior to analysis. We assigned each species to a growth form or family (forb, geophyte, Cyperaceae, Restionaceae, graminoids, low shrub $[<25 \mathrm{~cm}]$, mid-shrub [25-100 cm], or tall shrub $[>100 \mathrm{~cm}])$. These classifications were based on maximum heights listed in field guides and the South African National Biodiversity Institute database (Manning, 2007; Manning and Goldblatt, 2012; SANBI, 2009). Alien species were placed in a separate category. For each of the treatment categories (cleared plantation, cleared fynbos, reference disturbed, and reference pristine), we summed the cover class midpoints of all species per plot by growth form, and calculated mean values per treatment.

\subsection{Statistical and descriptive analyses}

All analyses were performed in $\mathrm{R}$ version 3.2.3 ( $\mathrm{R}$ Development Core Team, 2015). We ran a glm with the Poisson distribution and a false discovery rate correction to test for differences in species richness per plot among the four plot types (multcomp package). We described the frequency (number of plots) and cover of the most common species (those occurring in at least 8 plots of one type). We used Kruskal-Wallis tests to test for differences in total cover, and in average cover of growth forms per plot among the four 


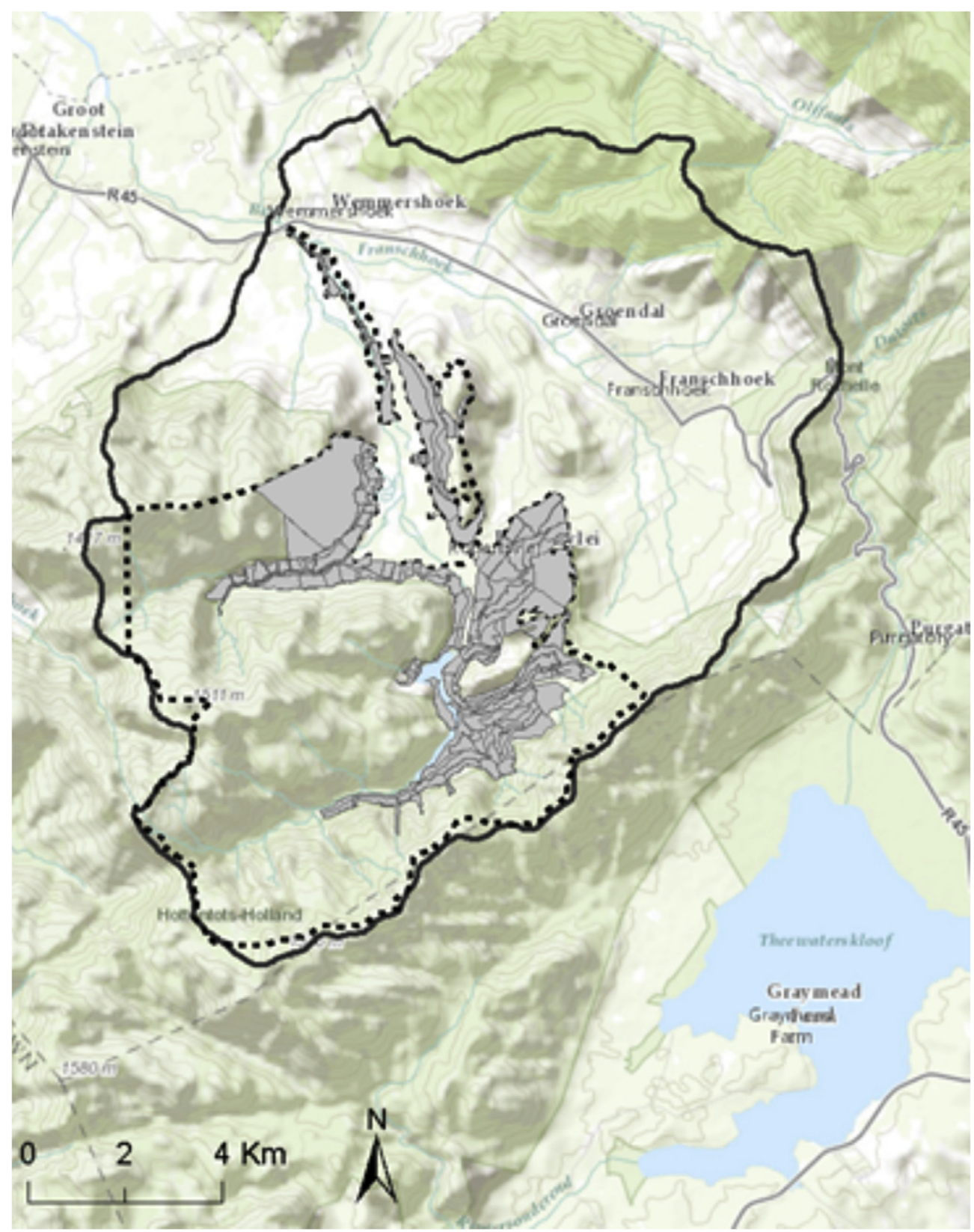

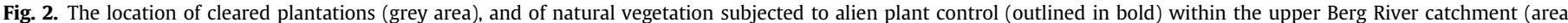
within dotted outline).

treatment categories (cleared plantation, cleared fynbos, reference disturbed, reference pristine); those that were significant were subjected to post-hoc multiple comparison tests (Dunn's test, package dunn.test).

Finally, we generated a Gower dissimilarity matrix, modified for ordinal data (package FD; Podani, 1999). We used nonmetric multidimensional scaling (NMDS) and analysis of similarity (anosim; package vegan) to examine differences in species composition and growth form among the four treatment categories.

\section{Results}

\subsection{Goals of management}

The goals of the ecosystem restoration project in the Berg River catchment were never explicitly recorded, and there was no formal management plan to guide operations. The project was initiated primarily in response to the withdrawal of formal plantation activities in the area (Louw, 2006), with the intention of transferring responsibility for the land to the provincial conservation agency. In addition, research had recently demonstrated that more water could be delivered, at a lower unit cost, by integrating alien plant management into the development and maintenance of water supply infrastructure, and this was regarded as a key issue in the planning for the Berg River dam (van Wilgen et al., 1997). These two factors made the Berg River catchment an excellent candidate for the implementation of alien plant control projects under the auspices of the government's Working for Water programme (van Wilgen and Wannenburgh, 2016). While the goals of management were not spelt out, they were implicitly aligned with the 
higher-level goals of Working for Water, and they included the intent to reduce the impact of invasive alien species on water resources (Le Maitre et al., 2002; Marais and Wannenburg, 2008), to protect or restore native species in a biodiversity hotspot (van Wilgen, 2013), and to provide employment opportunities (van Wilgen and Wannenburgh, 2016). For this specific project, however, the spatial extent of the intended control, the timeframe within which control was to be achieved, and the allocation of resources to management remained subject to the interpretation of individuals who were funding and implementing the project.

\subsection{Elements of best practice}

Several studies of ecosystem restoration following alien plant clearing in fynbos shrublands have been conducted over the past 20 years. A review of these studies reveals some general principles that should underpin any restoration effort. Broadly, the problem species are in two categories. The first, which includes Pinus species, are characterised by an inability to re-sprout following felling, short juvenile periods, and wind dispersal via winged seeds. Bestpractice control involves pre-fire felling of mature trees; given the extent of the invasions, it is regarded as essential to use power tools (chainsaws and brushcutters) on non-steep slopes, rather than hand tools such as axes or handsaws (Fenn, 1980). Seeds are released from cones after felling, and the area should be burned after $1-2$ years (which kills any resultant seedlings before they can mature; Holmes et al., 2000). No herbicide treatments are necessary as the trees do not re-sprout. No biological control agents are available for Pinus, due to concerns about the impact they may have on the forest industry (Hoffmann et al., 2011). The second category, which includes Acacia species, includes plants that produce an abundance of seeds that build up in the soil (Richardson and Kluge, 2008). Initial felling needs to be followed by the application of herbicides to cut stumps to prevent re-sprouting. The seeds are stimulated to germinate en masse by fires, so burning can dramatically increase the number of seedlings that germinate. Felling followed by burning can be used to deplete soil-stored seed banks, but requires repeated follow-up weeding of emergent seedlings. Alternatively, seedlings can be weeded by hand without burning. A suite of seed-feeding weevils and gall-forming flies and wasps (which prevent seed production by inducing the formation of galls instead of seed pods), have significantly reduced the seed output of many invasive Acacia species, increasing the probability of achieving sustainable control (Moran and Hoffmann, 2011). Because seeds are spread by water along drainage lines, it is best to initiate clearing operations at the highest point in the catchment, and to work downstream.

Research has also examined the relative merits of clearing alien plant invasions of differing densities on the effectiveness of control operations (Higgins et al., 2000). This research generally indicates that the most cost-effective approach is to prioritize clearing efforts on scattered rather than dense invasions (van Wilgen et al., 2000). In the Berg River catchment, scattered invasions tended to occur on steep slopes and in inaccessible areas, and additional training is required to work in these areas. Working for Water established "high altitude" teams in response to this need, and the activities of these teams should be integrated with those of teams working in more accessible, relatively flat areas.

Most invasive alien plant clearing operations in fynbos ecosystems have relied on passive restoration, where the recovery of natural vegetation relies on in situ survival of individual plants, regeneration from surviving soil-stored seed, or dispersal from outside of the cleared area. However, where alien plant invasions have been allowed to reach high densities for long periods, most native species are extirpated, and soil seed banks of long-lived species have become depleted (Holmes, 2002). In these cases, the active re-introduction of under-represented plant groups, especially obligate re-seeding plants such as those in the family Proteaceae, is regarded as an essential element of best practice (Gaertner et al., 2011; Holmes and Richardson, 1999).

\subsection{Adherence to best practice}

The implementation of control operations in the Berg River catchment was characterised by the use of some, but not all, of the elements of best practice. On the positive side, the control of invasive Pinus species outside of the cleared plantations was initially prioritized to target sparsely-invaded areas first, while the clearing of Acacia species progressed through the catchment systematically, beginning in the upper reaches of the catchment. Other activities either deviated from best practice, or best practice techniques were not used at all. The decision in 2012 to separate the management of inaccessible and high altitude areas (and by implication the scattered portions of the invaded area) also resulted in a lack of co-ordination, and an inability to prioritize sparselyinvaded areas (see section 3.4). The use of power tools was also limited to only one person in a team of 10 , while the remaining workers had to use hand tools. The use of fire was limited to biomass-reduction burns following clearing in densely infested areas (along the river), and there were no prescribed burns aimed at removing alien plant seedlings higher in the catchment. As a result, many more follow-up treatments were required to remove seedlings that could arguably have been removed more effectively, and at a much lower cost, by burning the cleared areas once the seeds had germinated. There was also no active reseeding or replanting of native species.

\subsection{Area treated and costs}

At the time that the Berg River project was initiated, alien Pinus trees occurred at a range of densities on approximately 7500 ha in the project area (Table 1$)$. About $25 \%$ of this area ( 1900 ha) supported either dense or medium infestations of Pinus ( $>25 \%$ cover). Alien Acacia trees occurred on just over 6000 ha, but dense or medium infestations covered a smaller area than Pinus (about 650 ha, or $11 \%$ of the project area). Control costs amounted to nearly ZAR 28 million for Pinus, and to over ZAR 21 million for Acacia trees (Table 1). The percentage of the annual budget that was allocated to high elevation clearing was $28 \%, 22 \%$, and $6 \%$ for 2012,2013 , and 2014 , respectively. Ideally, these percentages should have been higher to achieve the necessary focus on sparsely-invaded areas. Unfortunately, a lack of records does not allow for an assessment of the areas or species treated by the high altitude teams. Although invasive Acacia trees with high cover occupied much less area than Pinus (11 vs 25\%), costs for clearing were not that different (ZAR 28 vs 21 million). This reflects the higher costs per unit area to clear Acacia trees, as they require the application of herbicides to cut stumps, and more follow-up treatments to remove seedlings that constantly emerge from the soil. Areas cleared of invasive Pinus trees received up to 15 follow-up weeding treatments (typically two - five treatments), in areas of high or low cover (Fig. 3). Invasions of Acacia trees with low cover were typically followed up between three and seven times, while areas with higher levels of cover were followed up more frequently (8-16 times, Fig. 3).

\subsection{Effectiveness of control}

Clearing operations in the upper Berg River catchment have substantially reduced the cover of invasive alien trees (Fig. 4). However, much remains to be done. Despite significant amounts 
Table 1

The initial extent of alien plant invasions in the upper Berg River catchment and the costs of control.

\begin{tabular}{|c|c|c|c|}
\hline \multirow[t]{2}{*}{ Genus } & \multicolumn{2}{|l|}{ Initial area occupied (ha) } & \multirow[t]{2}{*}{ Cost of control 2001-2014 (2015 ZAR) } \\
\hline & Medium-dense (>25\%) & Low-scattered (1-25\%) & \\
\hline Pinus & 1882 & 5642 & 27971342 \\
\hline Acacia & 657 & 5368 & 21833247 \\
\hline
\end{tabular}

Pinus

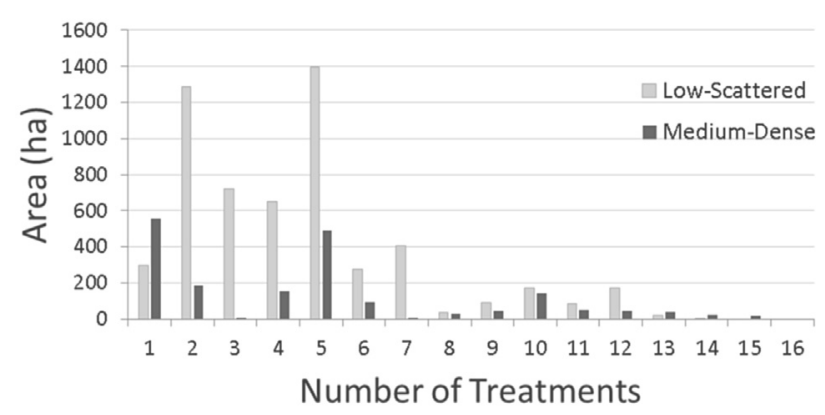

Acacia

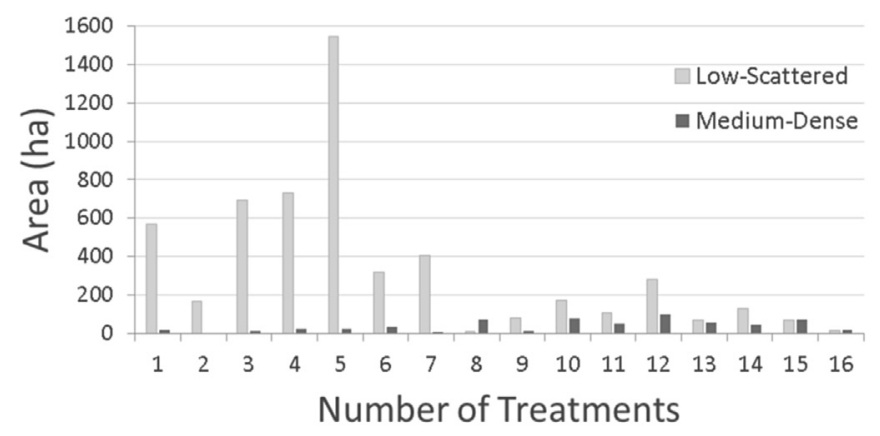

Fig. 3. The area of (a) Pinus and (b) Acacia trees in two categories of cover (mediumdense $=26-100 \%$ cover; low-scattered $=1-25 \%$ cover) subjected to different numbers of follow-up treatments in the Berg River catchment between 2001 and 2014.

having been expended on clearing and on follow-up, an estimated 419 ha of dense and medium-cover Pinus trees, and 679 ha of Acacia trees remain (the estimated cover of Acacia trees in the medium category actually increased by $174 \mathrm{ha}$ ). Some change in Acacia cover, particularly on high slopes, was likely due to germination after fires, several of which occurred in the catchment during this period. In addition, the area occupied by scattered pines increased by more than 3000 ha to $>5700$ ha (some of this was due to reductions in cover of areas previously mapped as dense, medium or low cover). Native trees and shrubs have recovered in riparian zones that previously supported a relatively high cover of Acacia trees (Fig. 5). Young Pinus trees were still evident across most of the catchment, particularly at higher altitudes (Fig. 6).

\subsection{Vegetation recovery}

Alien plant control, and a reliance on passive restoration, has not yet resulted in the successful restoration of all elements of native species diversity. Plots in reference sites were characterised by relatively high species diversity at a plot level (a mean of 32 species per plot, Table 2), significantly higher than at the two cleared sites $(p=0.00)$. Cleared fynbos plots in the Berg River had $25 \%$ fewer species per plot (24) than the reference sites, while cleared plantations had $40 \%$ fewer species per plot (19) than reference sites $(p=0.00)$. Overall overlapping canopy cover on cleared or
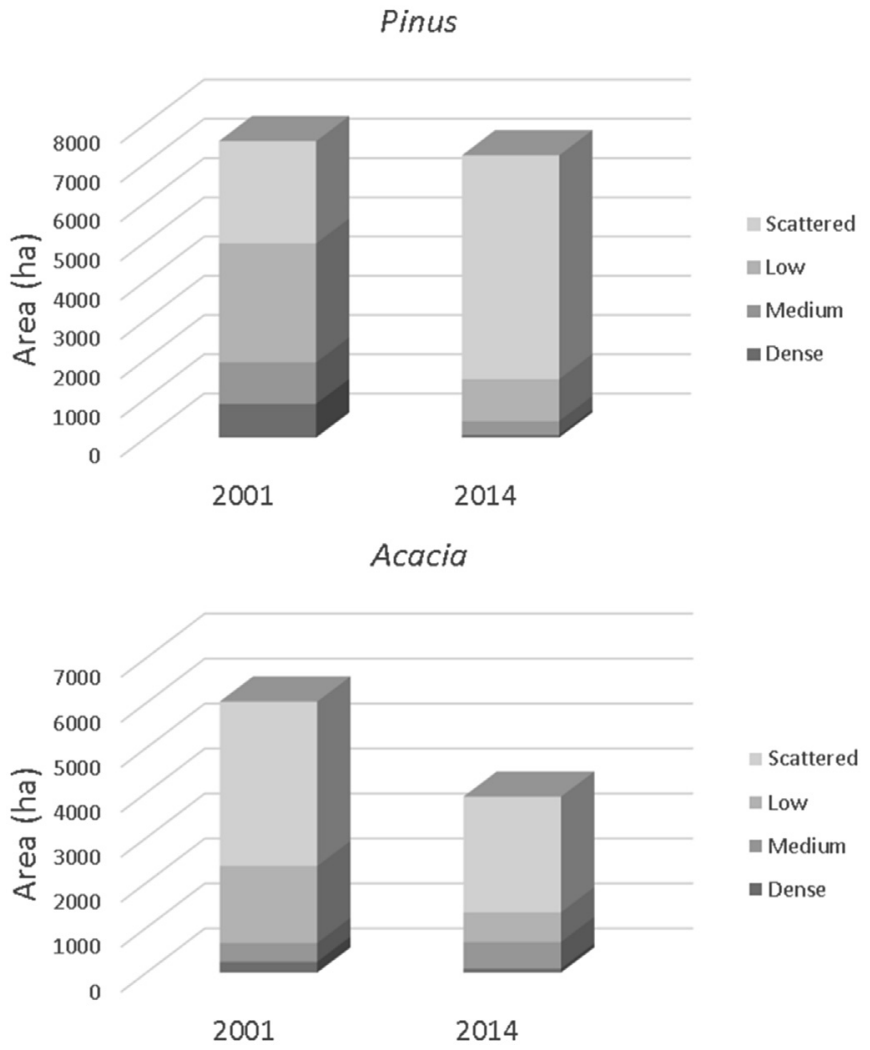

Fig. 4. Area occupied by alien Pinus and Acacia trees at different levels of cover in the upper Berg River catchment at the initiation of a control project in 2001, and after 13 years of treatments in 2014. Cover levels are dense (>50\% cover), medium (26-50\% cover), low (6-25\% cover) and scattered ( $0.5-5 \%$ cover).

previously disturbed sites was also lower (70-108\%) than on the pristine reference site (168\%, Table 2 ). The most marked difference was in tall shrubs, which covered roughly $90 \%$ in the reference pristine site, compared to $15-30 \%$ in cleared sites. Most of these shrubs were obligate re-seeding Protea shrubs, although Protea nitida (a tall shrub that is able to resprout after fire) was also negatively affected by invasion, and had not returned to cleared sites. Low and mid-shrubs in the genus Erica appeared less affected. The mid-shrub Stoebe plumosa, an indicator of disturbed sites, occurred more frequently, and at higher cover, on cleared plots than on reference sites. In addition, alien species were still evident on most plots in the Berg catchment, but absent from plots in the reference sites. However, total species diversities were similar across all sites, although the suite of co-occurring species differed, as indicated by the separation of plant communities in the NMDS plot (Fig. 7A). Cleared fynbos and cleared plantation plots were more similar to each other than to the reference plots both in composition of species with cover class midpoints greater than $15 \%$ (R-0.3829, $\mathrm{p}=0.001$; Fig. $7 \mathrm{~A})$ and in cover by growth form $(R=0.4812, p=0.001$; Fig. 7B $)$. 

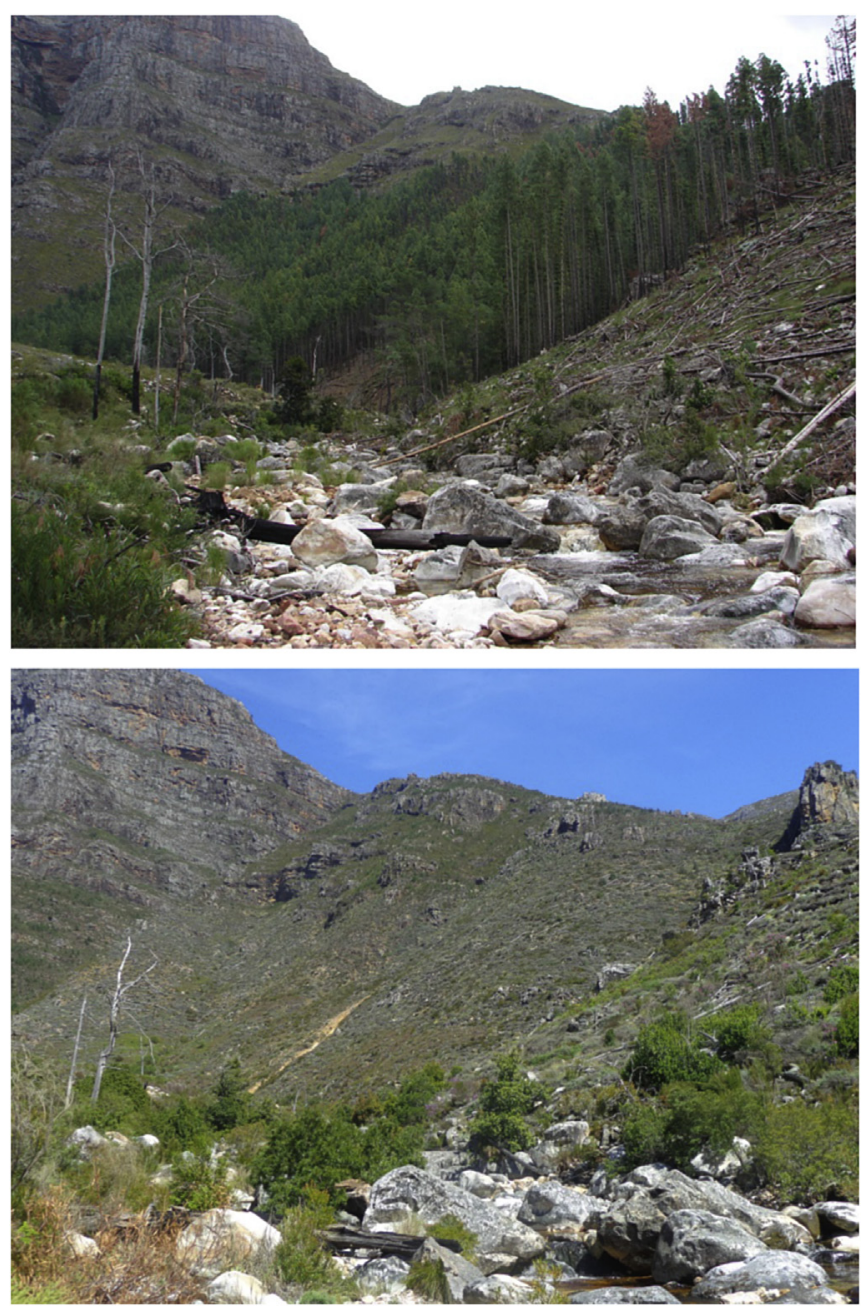

Fig. 5. Section of the Berg River catchment in May 2008 (top) and October 2015 (bottom). Planted Pinus trees have been removed, and invasive trees have been repeatedly cleared from adjacent unplanted areas in the background. Recovery of native trees along the riparian zone is evident (Photographs: G.G. Forsyth).

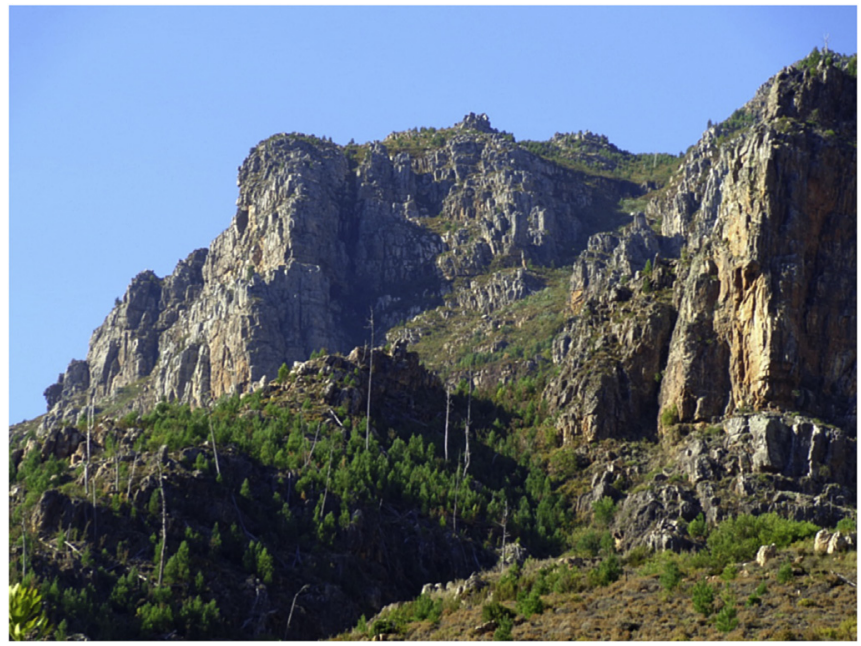

Fig. 6. Upper slopes of the Berg River catchment showing regenerating Pinus trees in areas that have been previously cleared and followed up. (Photograph: G.G. Forsyth)

\section{Discussion}

\subsection{Effectiveness of control}

Large sums of money are spent annually around the world on alien plant and animal control projects, but their effectiveness in the medium to long term is seldom reported, especially in the scientific literature (Menz et al., 2013). In the case that we considered here, it is clear that while there has been some progress, much remains to be done to ensure a sustainable outcome, despite substantial and sustained funding. In the Berg River project, as with other similar alien plant control projects in South Africa, a sustainable outcome is regarded as the achievement of a low level of invasion that could be contained at a relatively low cost in perpetuity. Often referred to as a "maintenance level" (Department of Environmental Affairs, 2016), this goal recognises that alien species, once established, cannot be eradicated (Simberloff et al., 2005). It should be possible, however, for management agencies to raise sufficient funding to ensure the ongoing protection of ecosystem services (for example by adding a levy to the price of water, see Turpie et al., 2008), provided that invasions are reduced to a maintenance level. It is unlikely that the current levels of funding will be sustained for long enough to reach this level at the current rate of progress, and if the funding were to decline in the near future, it is possible that the upper Berg River catchment would rapidly become re-invaded.

Our assessment has shown that, unless best practice is followed, it is extraordinarily difficult to achieve effective alien plant control and ecosystem restoration, even with a large budget. Evidence suggests that this is true for many areas of the Western Cape (van Wilgen et al., 2012; van Wilgen et al., 2016). A failure to achieve the goal of reducing plant invasions in the Berg and other catchments would have serious negative consequences. First, an increase of invasions could reduce water resources by up to $36 \%$, severely constraining the growth of local economies and impacting on quality of life in the major towns and cities in the CFR (Le Maitre et al., 1996; van Wilgen et al., 2008). Secondly alien plant invasions would erode biodiversity in a recognised hotspot (Raimondo et al., 2009; van Wilgen et al., 2008), reducing the resilience of the ecosystem and its ability to deliver services. Finally, alien plant invasions increase fuel loads and thus the severity of wildfires (common in the region), with significant economic and safety implications (Nel et al., 2014; van Wilgen and Scott, 2001). To avoid these consequences, it will be necessary to ensure a better adherence to best practice, as discussed in section 4.2 below.

\subsection{Recommendations for improving the effectiveness of control}

If ecosystem restoration is to be achieved, then adherence to best practice would almost certainly be essential (section 3.2). Establishing explicit operational goals should be a first step in determining how these methods should be applied. These goals should set measurable targets to be achieved within a defined timeframe, and incorporated into a comprehensive management plan for the catchment. Notably, a management plan is currently being drafted for this project (M. Paulsen, personal communication). We make several recommendations for this process.

Fire is a cost-effective method for controlling non-sprouting alien plants and stimulating vegetation recovery (Richardson and van Wilgen, 1986b). It can be substantially cheaper than mechanical activities (Musil et al., 2005), especially on steep slopes and inaccessible areas. Although there are risks associated with prescribed fire, the threats posed by invasive alien plants are arguably greater and are even exacerbated by the occurrence of unplanned wildfires (van Wilgen, 2009). In the case of low-density invasive 
Table 2

Comparison of plant species occurrence, richness and cover statistics on plots $(5 \times 10 \mathrm{~m})$ following four treatments in fynbos shrublands $(\mathrm{n}=15$ plots per treatment).

\begin{tabular}{|c|c|c|c|c|}
\hline \multirow[t]{2}{*}{ Statistic } & \multicolumn{4}{|l|}{ Treatment } \\
\hline & Cleared planted & Cleared fynbos & Reference disturbed & Reference pristine \\
\hline Mean native species richness/plot ${ }^{1}$ & $19^{a} \pm 1$ & $24^{\mathrm{b}} \pm 1$ & $31^{c} \pm 1$ & $33^{c} \pm 1$ \\
\hline Mean total percent cover/plot & $70.7^{\mathrm{a}}$ & $108^{\bar{a}}$ & $104^{\bar{a}}$ & $168^{\bar{b}}$ \\
\hline Total number of native species & 113 & 163 & 134 & 145 \\
\hline Total number of alien species & 3 & 4 & 0 & 0 \\
\hline Mean percent cover of graminoids & $7.6^{\mathrm{ab}}$ & $7.4^{\mathrm{a}}$ & $6.9^{\mathrm{a}}$ & $15.9^{\mathrm{b}}$ \\
\hline Mean percent cover of restioids & $4.5^{\mathrm{a}}$ & $22.7^{\mathrm{b}}$ & $30.5^{\mathrm{b}}$ & $16.4^{\mathrm{b}}$ \\
\hline Mean percent cover of forbs & $13.4^{\mathrm{ab}}$ & $7.97^{\mathrm{a}}$ & $4.5^{\mathrm{a}}$ & $24.9^{b}$ \\
\hline Mean percent cover of tall shrubs & $15.5^{\mathrm{a}}$ & $30.6^{a}$ & $32.6^{\mathrm{a}}$ & $89.6^{\mathrm{b}}$ \\
\hline Occurrence of obligate reseeding Protea species (tall shrubs) ${ }^{2}$ & 0 & $1(0.2)$ & $7(0.5)$ & $12(31)$ \\
\hline Occurrence of Protea nitida (resprouting tall shrub) ${ }^{2}$ & 0 & $1(1.0)$ & $6(6.7)$ & $8(5.1)$ \\
\hline Occurrence of Erica species (low and mid-shrubs) ${ }^{2}$ & $11(4.1)$ & $14(14.5)$ & $9(4.9)$ & $14(6.5)$ \\
\hline Occurrence of Stoebe plumosa (mid-shrub) ${ }^{2}$ & $14(5.8)$ & $13(5.7)$ & $7(1.4)$ & $3(1.4)$ \\
\hline
\end{tabular}

${ }^{1}$ Mean \pm standard error, rounded to the nearest integer. Means with the same superscript do not differ significantly.

${ }^{2}$ Number of plots, with mean percent cover in parentheses.

pines and hakeas in mature fynbos vegetation, a single fire two years after initial felling would remove almost all pine seedlings that emerge after felling at a fraction of the cost of multiple followup treatments as currently applied (Fig. 3), thereby substantially increasing the effectiveness of control. Handpulling of seedlings would be more appropriate after felling dense invasive stands or plantations, where indigenous seed banks would have been depleted, and where fire intensity would be increased by elevated fuels loads brought about by invasion and clearing. In such cases, handpulling instead of burning would reduce the risk of destroying the few remaining indigenous plant seeds (Holmes et al., 2000; Richardson and van Wilgen, 1986b).

Power tools such as chainsaws and brushcutters should also be favoured for non-sprouting alien plants (pines and hakeas) over labour-intensive tools such as handsaws and axes where appropriate, or at least in less steep areas. Currently, the use of power tools is minimised because of the need for additional training and safety precautions, resulting in large inefficiencies. Finally, the separate operations aimed respectively at accessible and less accessible areas should be coordinated, with more resources going to the clearing of scattered invasions where the returns on investment would be far greater (McConnachie et al., 2016).

It is clear that active restoration will also be necessary to restore missing components of fynbos vegetation. Our species richness numbers are similar to those of Pinus-invaded and uninvaded sites sampled by Richardson et al. (1989). Species richness declines with invasion duration (Holmes and Cowling, 1997), and may still be significantly lower than uninvaded fynbos even after clearing (Richardson et al., 1989). Acacia invasions elevate soil nitrogen levels which are less favorable to proteoid and ericoid shrubs than to grasses, forbs, and other shrubs (Gaertner et al., 2012). A number of species, especially those in the genus Protea, are eliminated by dense invasions, along with their seed pools, and will need to be reintroduced (Holmes and Cowling, 1997; Richardson and van Wilgen, 1986a). This can be done by harvesting and scattering local seed (Holmes and Richardson, 1999). Erica species can persist for longer time periods but eventually decline with canopy closure (Holmes and Cowling, 1997). Although re-seeding species may persist for long periods of time as seeds in the soil, including some Proteaceae and Ericaceae species (Holmes and Newton, 2004), fire stimulates germination in others, including species of Restionaceae, Fabaceae, and Asteraceae (Brown et al., 1994; Brown and Botha, 2004). Thus, lack of prescribed fire in management plans may inhibit successful restoration of certain species.

The management approach could also be substantially improved by changes to the current employment model. The current practice of awarding contracts for clearing individual management units results in discontinuous employment opportunities interspersed with periods of unemployment while the next contract is being secured. Because wages are higher for other seasonal work particularly during the summer months, workers on clearing teams leave after a winter season and do not necessarily return the following season. Thus, training (including power tool instruction) is provided every year to a new group of employees, making this an annual cost. Instead, workers could be paid better wages to stay on throughout the year and training costs would be lower. Additionally, if high and low elevation areas continue to be cleared by different agencies, the same intensive training should be supplied to all teams.

Finally, long-term planning and monitoring activities are essential for evaluating the effectiveness of best practice approaches (McConnachie et al., 2012). Periodic assessments over the long term should reveal whether alien plant spread is under control and if re-established fynbos plant populations are self-sustaining (Holmes and Richardson, 1999). Monitoring should also include quality control for diligence in applying clearing and restoration treatments in the field (Kraaij et al., 2017; McConnachie et al., 2012). In addition to requiring reports of monitoring results, a management plan should describe contingency plans and monitoring schedules in the event of likely scenarios such as budget cuts and unplanned wildfires.

\subsection{The need for assessments}

Globally, there is a growing recognition that scarce funding for conservation needs to be spent more effectively (Bottrill et al., 2008; Murdoch et al., 2007; Wilson et al., 2006). Coupled to this, there is a need to document the outcomes of actual projects, and to learn from them (Palmer et al., 2007; Suding et al., 2015). Even if initial project goals are not achieved, monitoring the ecological results of an approach assists subsequent resource allocation decisions (Bryan et al., 2009; Saunders and Norton, 2001; Shafer and Bergstrom, 2010). Other large-scale projects have illustrated the importance of informed approaches for ensuring sustainable, costeffective restoration outcomes. The evolution of restoration activities in Brazilian Atlantic forests illustrates how advances in ecological understanding over time improved outcomes in terms of lower costs and sustainable native plant restoration (Rodrigues et al., 2009). However, although there have been calls for information dissemination, the outcomes of restoration projects are not often used to inform practice (Knight et al., 2006; Menz et al., 2013), and case studies are rare (Knight et al., 2006; Palmer et al., 2007). 

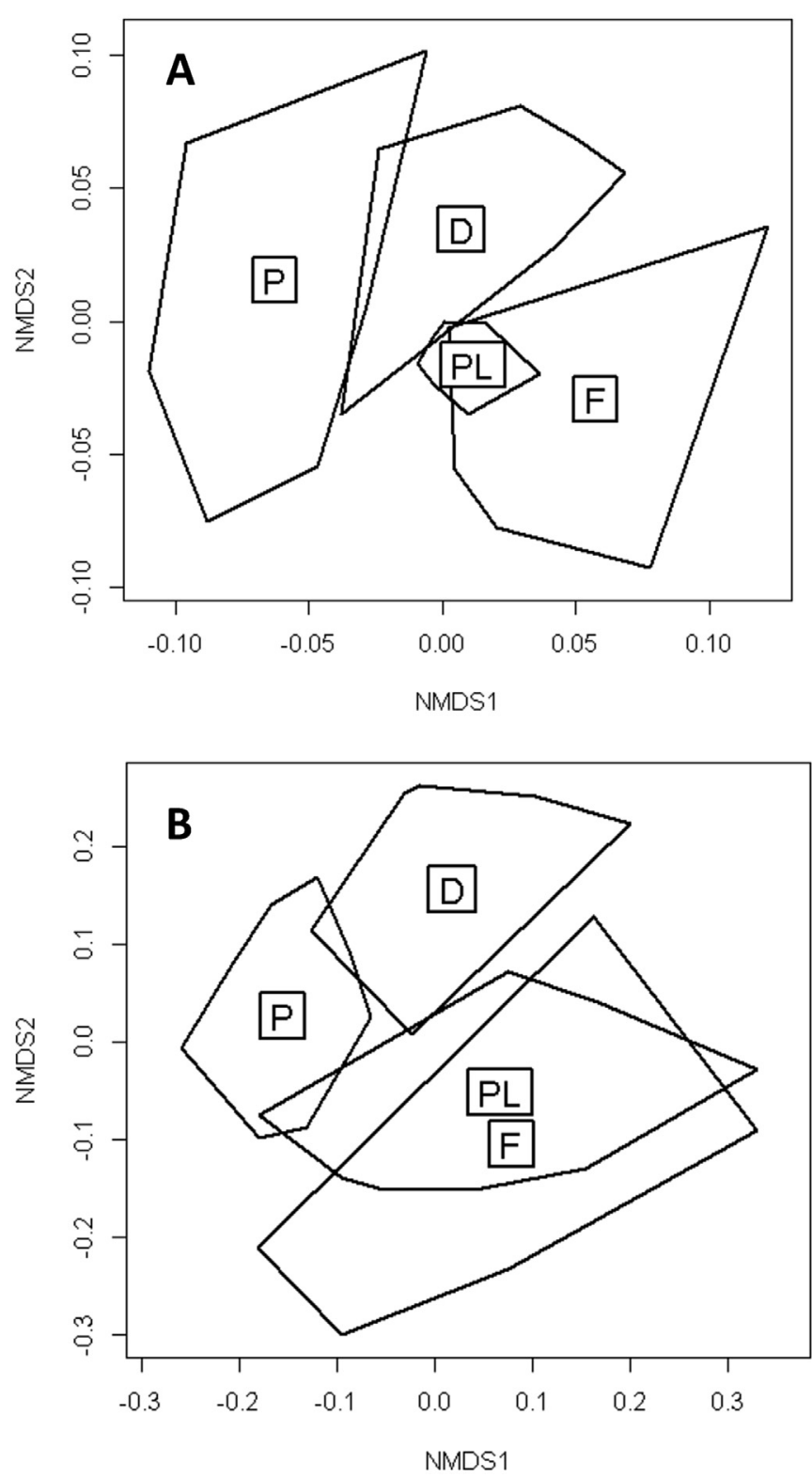

Fig. 7. Nonmetric multidimensional scaling (NMDS) of species cover class midpoints in the four groups using A) species with values of $15 \%$ or more and B) growth form cover per plot ( $\mathrm{P}$, reference pristine; $\mathrm{D}$, reference disturbed; PL, cleared planted; $\mathrm{F}$, cleared fynbos). Polygons show convex hull of the plots in each group.

Our assessment has demonstrated how case studies can lead to practical recommendations to improve the efficacy of restoration and management projects. Moreover, our results contribute to a broader assessment of how well a national-level management framework promotes invasion control and ecosystem restoration. Therefore, our study should provide additional impetus for assessing restoration projects not only in South Africa, but also in other parts of the world where alien plant control or restoration are priorities for management (Dukes and Mooney, 2004; Grice, 2004; Williams and West, 2000). For example, both New Zealand and Australia have national invasive alien plant policy frameworks to guide management. Assessments of control measures and outcomes are absolutely essential for identifying effective management strategies and providing recommendations to improve policy (e.g., Odom et al., 2003; Vitelli and Pitt, 2006).

\section{Acknowledgements}

We thank Manfred Paulsen, Jason de Smidt, Dave McDonald, and Douglas Euston-Brown for advice and access to historical plot data. Funding was provided by the DST-NRF Centre of Excellence for Invasion Biology and the Working for Water Programme through their collaborative research project on "Integrated Management of invasive alien species in South Africa", and the National Research Foundation (grant 87550 to BWvW). Maps were created using ArcGIS $^{\circledR}$ software by Esri. ArcGIS ${ }^{\circledR}$ and ArcMap ${ }^{\mathrm{TM}}$ are the intellectual property of Esri and are used herein under license. Copyright ${ }^{\circledR}$ Esri. All rights reserved.

\section{References}

Bottrill, M.C., Joseph, L.N., Carwardine, J., Bode, M., Cook, C., Game, E.T., Grantham, H., Kark, S., Linke, S., McDonald-Madden, E., Pressey, R.L., 2008. Is conservation triage just smart decision making? Trends Ecol. Evol. 23, 649-654.

Brown, N.A.C., Jamieson, H., Botha, P.A., 1994. Stimulation of seed germination in South African species of Restionaceae by plant-derived smoke. Plant Growth Regul. 15, 93-100.

Brown, N.A.C., Botha, P.A., 2004. Smoke seed germination studies and a guide to seed propagation of plants from the major families of the Cape Floristic Region, South Africa. S. Afr. J. Bot. 70, 559-581.

Brudvig, L.A., 2011. The restoration of biodiversity: where has research been and where does it need to go? Am. J. Bot. 98, 549-558.

Bryan, B.A., Kandulu, J., Deere, D.A., White, M., Frizenschaf, J., Crossman, N.D., 2009. Adaptive management for mitigating Cryptosporidium risk in source water: a case study in an agricultural catchment in South Australia. J. Environ. Manag. 90, 3122-3134.

Clewell, A.F., Aronson, J., 2007. Ecological Restoration: Principles, Values, and Structure of an Emerging Profession, first ed. Island Press, Washington, D.C.

Department of Environmental Affairs., 2016. https://www.environment.gov.za/ projectsprogrammes/wfw/invasiveplant $>\mathrm{L}>$ (accessed 22.05.16).

Dukes, J.S., Mooney, H.A., 2004. Rev, Chil. Hist. Nat. 77, 411-437.

Epanchin-Niell, R.S., Hastings, A., 2010. Controlling established invaders: integrating economics and spread dynamics to determine optimal management. Ecol. Lett. 13, 528-541.

Fenn, J.A., 1980. Control of hakea in the Western Cape. In: Neser, S., Cairns, A.L.P. (Eds.), Proceedings of the Third National Weeds Conference of South Africa. Balkema, Cape Town, South Africa, pp. 167-173.

Gaertner, M., Richardson, D.M., Privett, S.D.J. 2011. Effects of alien plants on ecosystem structure and functioning and implications for restoration: insights from three degraded sites in South African fynbos. Environ. Manag. 48, 57-69.

Gaertner, M., Nottebrock, H., Fourie, H., Privett, S.D.J., Richardson, D.M., 2012. Plant invasions, restoration, and economics: perspectives from South African fynbos. Perspect. Plant Ecol. Evol. Syst. 14, 341-353.

Grice, A.C., 2004. Weeds and the monitoring of biodiversity in Australian rangelands. Austral Ecol. 29, 51-58.

Higgins, S.I., Richardson, D.M., Cowling, R.M., 2000. Using a dynamic landscape model for planning the management of alien plant invasions. Ecol. Appl. 10, 1833-1848.

Hoffmann, J.H., Moran, V.C., van Wilgen, B.W., 2011. Prospects for biological control of invasive Pinus species (Pinaceae) in South Africa. Afr. Entomol. 19, 393-401.

Holl, K.D., Aide, T.M., 2011. When and where to actively restore ecosystems? For. Ecol. Manag. 261, 1558-1563.

Holmes, P.M., 2002. Depth distribution and composition of seed-banks in alieninvaded and uninvaded fynbos vegetation. Austral Ecol. 27, 110-120.

Holmes, P.M., Cowling, R.M., 1997. The effects of invasion by Acacia saligna on the guild structure and regeneration capabilities of South African fynbos shrublands. J. Appl. Ecol. 34, 317-332.

Holmes, P.M., Richardson, D.M., 1999. Protocols for restoration dynamics, community structure and ecosystem function: perspectives from South African fynbos. Restor. Ecol. 7, 215-230.

Holmes, P.M., Newton, R.J., 2004. Patterns of seed persistence in South African fynbos. Plant Ecol. 172, 143-158.

Holmes, P.M., Richardson, D.M., van Wilgen, B.W., Gelderblom, C., 2000. The recovery of South African fynbos vegetation following alien tree clearing and fire: implications for restoration. Austral Ecol. 25, 631-639.

Knight, A.T. Driver, A., Cowling, R.M., Maze, K., Desmet, P.G., Lombard, A.T. Rouget, M., Botha, M.A., Boshoff, A.F., Castley, J.G., Goodman, P.S., Mackinnon, K., Pierce, S.M., Sims-Castley, R., Stewart, W.I., von Hase, A., 2006. Designing systematic conservation assessments that promote effective implementation: best practice from South Africa. Conserv. Biol. 20, 739-750.

Koenig, R., 2009. Unleashing an army to repair alien-ravaged ecosystems. Science $325,562-563$.

Kraaij, T., Baard, J.A., Rikhotso, D.R., Cole, N., van Wilgen, B.W., 2017. Assessing the effectiveness of alien plant management in a large fynbos protected area. Bothalia Afr. Biodivers. Conserv. 47 (in press).

Küchler, A.W., 1967. Vegetation Mapping, first ed. Ronald Press, New York. 
Le Maitre, D.C., van Wilgen, B.W., Chapman, R.A., McKelly, D., 1996. Invasive plants and water resources in the Western Cape Province, South Africa: modelling the consequences of a lack of management. J. Appl. Ecol. 33, 161-172.

Le Maitre, D.C., van Wilgen, B.W., Gelderblom, C.M., Bailey, C., Chapman, R.A., Nel, J.A., 2002. Invasive alien trees and water resources in South Africa: case studies of the costs and benefits of management. For. Ecol. Manag. 160, 143-159.

Louw, W.J.A., 2004. General history of the South african forest industry: 1991 to 2002. South. Afr. For. J. 201, 65-76.

Louw, W.J.A., 2006. General history of the South african forest industry: 2003 to 2006. South. Afr. For. J. 208, 79-88.

Manning, J., 2007. Field Guide to Fynbos, first ed. Struik Nature, Cape Town.

Manning, J., Goldblatt, P., 2012. Plants of the Greater Cape Floristic Region 1: the Core Cape Flora. South African National Biodiversity Institute, Pretoria.

Marais, C., Wannenburg, A.M., 2008. Restoration of water resources (natural capital) through the clearing of invasive alien plants from riparian areas in South Africa-Costs and water benefits. S. Afr. J. Bot. 74, 526-537.

McConnachie, M.M., Cowling, R.M., van Wilgen, B.W., McConnachie, D.A., 2012. Evaluating the cost-effectiveness of invasive alien plant clearing: a case study from South Africa. Biol. Conserv. 155, 128-135.

McConnachie, M.M., van Wilgen, B.W., Richardson, D.M., Ferraro, P.J., Forsyth, T., 2015. Estimating the effect of plantations on pine invasions in protected areas: a case study from South Africa. J. Appl. Ecol. 52, 110-118.

McConnachie, M., van Wilgen, B.W., Gaertner, M., Richardson, D.M., Ferraro, P.J., Forsyth, A.T., Cowling, R.M., 2016. Measuring the cost-effectiveness of removing invasive plants through the use of counterfactual estimates. Ecol. Appl. 26, 475-483.

McDonald, D.J., 1985. The Plant Communities of Swartboschkloof, Jonkershoek. South African National Science Progress Report 104. CSIR, Pretoria.

Menz, M.H., Dixon, K.W., Hobbs, R.J., 2013. Hurdles and opportunities for landscapescale restoration. Science 339, 526-527.

Millenium Ecosystem Assessment, 2005. Ecosystems and Human Well-being, first ed. Island Press, Washington DC.

Moran, V.C., Hoffmann, J.H., 2011. Conservation of the fynbos biome in the Cape Floral Region: the role of biological control in the management of invasive alien trees. BioControl 57, 139-149.

Murdoch, W., Polasky, S., Wilson, K.A., Possingham, H.P., Kareiva, P., Shaw, R., 2007. Maximizing return on investment in conservation. Biol. Conserv. 139, 375-388.

Musil, C.F., Milton, S.J., Davis, G.W., 2005. The threat of alien invasive grasses to lowland Cape floral diversity: an empirical appraisal of the effectiveness of practical control strategies. S. Afr. J. Sci. 101, 337-344.

Nel, J.L., Le Maitre, D.C., Nel, D.C., Reyers, B., Archibald, S., van Wilgen, B.W., Forsyth, G.G., Theron, A.K., O'Farrell, P.J., Kahinda, J.-M.M., Engelbrecht, F.A., Kapangaziwiri, E., van Niekerk, L., Barwell, L., 2014. Natural hazards in a changing world: a case for ecosystem-based management. PLoS One 9, e95942.

Odom, D.I.S., Cacho, O.J., Sinden, J.A., Griffith, G.R., 2003. Policies for the management of weeds in natural ecosystems: the case of scotch broom (Cytisus scoparius, L.) in an Australian national park. Ecol. Econ. 44, 119-135.

Palmer, M., Allan, J.D., Meyer, J., Bernhardt, E.S., 2007. River restoration in the twenty-first century: data and experiential knowledge to inform future efforts. Restor. Ecol. 15, 472-481.

Perring, M.P., Standish, R.J., Price, J.N., Craig, M.D., Erickson, T.E., Ruthrof, K.X., Whiteley, A.S., Valentine, L.E., Hobbs, R.J., 2015. Advances in restoration ecology: rising to the challenges of the coming decades. Ecosphere 6,1-25.

Podani, J., 1999. Extending Gower's general coefficient of similarity to ordinal characters. Taxon 48, 331-340.

Raimondo, D., von Staden, L., Foden, W., Victor, J.E., Helme, N.A., Turner, R.C., Kamundi, D.A., Manyama, P.A., 2009. Red List of South African Plants. Strelitzia 25. South African National Biodiversity Institute, Pretoria.

Rebelo, A.G., Boucher, C., Helme, N., Mucina, L., Rutherford, M.C., 2006. Fynbos biome. In: Mucina, L., Rutherford, M.C. (Eds.), The Vegetation of South Africa, Lesotho, and Swaziland. South African National Biodiversity Institute, Pretoria, pp. 52-219.

Richardson, D.M., van Wilgen, B.W., 1986a. Effects of thirty-five years of afforestation with Pinus radiata on the composition of mesic mountain fynbos near Stellenbosch. S. Afr. J. Bot. 52, 309-315.

Richardson, D.M., van Wilgen, B.W., 1986b. The effects of fire in felled Hakea sericea and natural fynbos and implications for weed control in mountain catchments. S. Afr. For. J. 139, 4-14.

Richardson, D.M., Macdonald, I.A.W., Forsyth, G.G., 1989. Reductions in plant species richness under stands of alien trees and shrubs in the fynbos biome. S. Afr. For. J. 149, 1-8.

Richardson, D.M., Kluge, R.L., 2008. Seed banks of invasive Australian Acacia species in South Africa: role in invasiveness and options for management. Perspect. Plant Ecol. Evol. Syst. 10, 161-177.

Rodrigues, R.R., Lima, A.F., Gandolfi, S., Nave, A.G., 2009. On the restoration of high diversity forests: 30 years of experience in the Brazilian Atlantic Forest. Biol. Conserv. 142, 1242-1251.

Ruiz-Jaen, M., Aide, T.M., 2005. Restoration success: how is it being measured? Restor. Ecol. 13, 569-577.

Sainsbury, K.J., Punt, A.E., Smith, A.D.M., 2000. Design of operational management strategies for achieving fishery ecosystem objectives. ICES J. Mar. Sci. J. Conseil 57, 731-741.

Saunders, A., Norton, D.A., 2001. Ecological restoration at Mainland Islands in New Zealand. Biol. Conserv. 99, 109-119.

Shafer, D., Bergstrom, P., 2010. An introduction to a special issue on large-scale submerged aquatic vegetation restoration research in the Chesapeake Bay: 2003-2008. Restor. Ecol. 18, 481-489.

Simberloff, D., Parker, I.M. Windle, P.N., 2005. Introduced species policy, management, and future research needs. Front. Ecol. Environ. 3, 12-20.

South African National Biodiversity Institute, 2009. Plants of Southern Africa: an Online Checklist. http://posa.sanbi.org/tools.phpz. Accessed March 2016.

Stanturf, J.A., Palik, B.J., Dumroese, R.K., 2014. Contemporary forest restoration: a review emphasizing function. For. Ecol. Manag. 331, 292-323.

Suding, K., Higgs, E., Palmer, M., Callicott, J.B., Anderson, C.B., Baker, M., Gutrich, J.J., Hondula, K.L., LaFevor, M.C., Larson, B.M.H., Randall, A., Ruhl, J.B., Schwartz, K.Z.S., 2015. Committing to ecological restoration. Communities 8, 9.

Turpie, J.K., Marais, C., Blignaut, J.N., 2008. The working for water programme: evolution of a payments for ecosystem services mechanism that addresses both poverty and ecosystem service delivery in South Africa. Ecol. Econ. 65, 788-798.

van Wilgen, B.W., 2009. The evolution of fire and invasive alien plant management practices in fynbos. S. Afr. J. Sci. 105, 335-342.

van Wilgen, B.W., 2013. Fire management in species-rich Cape fynbos shrublands Front. Ecol. Environ. 11, e35-e44.

van Wilgen, B.W., Kruger, F.J., 1981. Observations on the effects of fire in mountain fynbos at Zachariashoek, Paarl. J. S. Afr. Bot. 47, 195-212.

van Wilgen, B.W., Kruger, F.J., 1985. Physiography and fynbos vegetation communities of the Zachariashoek catchments, south-western Cape Province. S. Afr. J Bot. 51, 379-399.

van Wilgen, B.W., Forsyth, G.G., 1992. Regeneration strategies in fynbos plants and their influence on the stability of community boundaries after fire. In: van Wilgen, B.W., Richardson, D.M., Kruger, F.J., van Hensbergen, H.J. (Eds.), Fire in South African Mountain Fynbos. Springer-Verlag, New York, pp. 54-80.

van Wilgen, B.W., Little, P.R., Chapman, R.A., Gorgens, A.H.M., Willems, T., Marais, C. 1997. The sustainable development of water resources: history, financial costs and benefits of alien plant control programmes. S. Afr. J. Sci. 93, 404-411.

van Wilgen, B.W., Scott, D.F., 2001. Managing fires on the Cape Peninsula: dealing with the inevitable. J. Mediterr. Ecol. 2, 197-208.

van Wilgen, B.W., Reyers, B., Le Maitre, D.C., Richardson, D.M., Schonegevel, L., 2008. A biome-scale assessment of the impact of invasive alien plants on ecosystem services in South Africa. J. Environ. Manag. 89, 336-349.

van Wilgen, B.W., Richardson, D.M., Higgins, S.I., 2000. Integrated control of invasive alien plants in terrestrial ecosystems. In: Preston, G., Brown, G., van Wyk, E. (Eds.), Best Management Practices for Preventing and Controlling Invasive Alien Species. Working for Water Programme, pp. 118-128. Cape Town.

van Wilgen, B.W., Forsyth, G.G., Le Maitre, D.C., Wannenburgh, A., Kotze, J.D.F., van den Berg, E., Henderson, L., 2012. An assessment of the effectiveness of a large, national-scale invasive plant control strategy in South Africa. Biol. Conserv. 148 28-38.

van Wilgen, B.W., Wannenburgh, A., 2016. Co-facilitating invasive species control, water conservation and poverty relief: achievements and challenges in South Africa's Working for Water programme. Curr. Opin. Environ. Sustain 19, 7-17.

van Wilgen, B.W., Fill, J.M., Baard, J., Cheney, C., Forsyth, A.T., Kraaij, T., 2016. Historical costs and projected future scenarios for invasive alien plant control in protected areas in the Cape Floristic Region. Biol. Conserv. 200, 168-177.

Vitelli, J.S., Pitt, J.L., 2006. Assessment of current weed control methods relevant to the management of the biodiversity of Australian rangelands. Rangel. J. 28, $37-46$.

Williams, J.A., West, C.J., 2000. Environmental weeds in Australia and New Zealand: issues and approaches to management. Austral Ecol. 25, 425-444.

Wilson, K.A., McBride, M.F., Bode, M., Possingham, H.P., 2006. Prioritizing global conservation efforts. Nat. Lett. 440, 337-340.

Wortley, L., Hero, J., Howes, M., 2013. Evaluating ecological restoration success: a review of the literature. Restor. Ecol. 21, 537-543. 